\title{
Is desire for social relationships mediated by the serotonergic system in the prefrontal cortex? An $\left[{ }^{18}\right.$ F $]$ setoperone PET study
}

\author{
Philip Gerretsen, Ariel Graff-Guerrero, and Mahesh Menon \\ University of Toronto, Toronto, Canada \\ Bruce G. Pollock \\ University of Toronto, and Rotman Research Institute, Toronto, Canada \\ Shitij Kapur \\ University of Toronto, Toronto, Canada, and King's College, London, UK \\ Neil Vasdev, Sylvain Houle, and David Mamo \\ University of Toronto, Toronto, Canada
}

\begin{abstract}
Social behavior and desire for social relationships have been independently linked to the serotonergic system, the prefrontal cortex, especially the orbitofrontal cortex (OFC), and the anterior cingulate cortex (ACC). The goal of this study was to explore the role of serotonin $5 \mathrm{HT}_{2 \mathrm{~A}}$ receptors in these brain regions in forming and maintaining close interpersonal relationships. Twenty-four healthy subjects completed the Temperament and Character Inventory (TCI) prior to undergoing $\left[{ }^{18} \mathrm{~F}\right]$ setoperone brain positron emission tomography (PET) to measure serotonin $5 \mathrm{HT}_{2 \mathrm{~A}}$ receptor availability within the OFC (BA 11 and 47) and ACC (BA 32). We explored the relationship between desire for social relationships, as measured by the TCI reward dependence (RD) scale, and $5 \mathrm{HT}_{2 \mathrm{~A}}$ receptor non-displaceable binding potential $\left(\mathrm{BP}_{\mathrm{nd}}\right)$ in these regions. Scores of $\mathrm{RD}$ were negatively correlated with $5 \mathrm{HT}_{2 \mathrm{~A}} \mathrm{BP}_{\mathrm{nd}}$ in the ACC (BA 32, $r=-0.528, p=0.012$ ) and OFC (BA 11, $r=-0.489, p=0.021$; BA 47, $r=-0.501, p=0.017$ ). These correlations were corroborated by a voxel-wise analysis. These results suggest that the serotonergic system may have a regulatory effect on the OFC and ACC for establishing and maintaining social relationships.
\end{abstract}

Keywords: Social behavior; Serotonin; Serotonin $5 \mathrm{HT}_{2 \mathrm{~A}}$ receptor; Orbitofrontal cortex; Anterior cingulate cortex; Positron emission tomography.

Correspondence should be addressed to: Ariel Graff-Guerrero, CAMH-PET Centre, 250 College Street, M5T 1R8, Toronto, Ontario, Canada. E-mail: Ariel_Graff@yahoo.com.mx

The authors thank Penny Baroum, Alan A. Wilson, Armando Garcia, Winston Stableford, Min Wong, Alvina Ng, Terry Bell, Ted HarrisBrandts, and Peter Bloomfield for their expert technical assistance. Funding of the PET camera system HRRT was supported by the Canada Foundation for Innovation, the Ontario Innovation Trust, and the Ontario Research and Development Challenge Fund.

PG, MM, NV, and SH report no biomedical financial interests or potential conflicts of interest. DM has received grants, consultant fees, or other financial support from the Canadian Psychiatric Research Foundation, the Schizophrenia Society of Canada, the Stanley Medical Research Institute, and Bristol-Myers Squibb, and has received speaker's honoraria from AstraZeneca within the past 5 years. SK has received grant support from AstraZeneca, Bristol-Myers Squibb, Eli Lilly, EMD-Darmstadt, GlaxoSmithKlein, Janssen, Neuromolecular Inc., and Pfizer, and has served as a consultant, scientific advisor, or speaker for AstraZeneca, Bristol-Myers Squibb, Eli Lilly, GlaxoSmithKlein, Janssen, Otsuka, Organon, Pfizer, Sanofi-Synthelabo, Servier, and Solvay Wyeth within the past 5 years. BGP serves on the advisory board of Lundbeck Canada and is a faculty member of the Lundbeck International Neuroscience Institute. AG-G has received professional services compensation from Abbott Laboratories and Janssen-Cilag.

(C) 2010 Psychology Press, an imprint of the Taylor \& Francis Group, an Informa business www.psypress.com/socialneuroscience

DOI: $10.1080 / 17470911003589309$ 


\section{INTRODUCTION}

Social relationships are fundamental to human survival (Bowlby, 1988). Social dependence is viewed by some researchers as a heritable personality trait (Cloninger, Svrakic, \& Przybeck, 1993), and by others as a product of early child development (Cassidy \& Shaver, 1999). Individuals dependent on social closeness are eager to help and please others, sympathetic, sentimental, and sensitive to praise and signs of rejection, while those who are socially and emotionally detached are content to be alone, practical, and selfreliant (Cloninger, 1987).

The functional neuroanatomy of desire for social relationships has yet to be fully elucidated. However, the orbitofrontal (OFC) and anterior cingulate cortices (ACC) have been implicated in social behavior (Harris, McClure, van den Bos, Cohen, \& Fiske, 2007; Hornak et al., 2003) and a number of other functions necessary to facilitate the successful formation and maintenance of social relationships, including reward assessment (Hampton \& O'Doherty, 2007; Kringelbach, 2005), self-regulation (Frankle et al., 2005; Posner, Rothbart, \& Sheese, 2007), attachment (Noriuchi, Kikuchi, \& Senoo, 2008), and the processing of emotion (Graff-Guerrero, Gonzalez-Olvera, Mendoza-Espinosa, Vaugier, \& Garcia-Reyna, 2004) and pain (Rainville, Duncan, Price, Carrier, \& Bushnell, 1997; Vogt, 2005). Neurochemically, social behavior has been associated with the serotonin (5HT) system. Animals exposed to serotonergic agents demonstrate more attachment behaviors, affiliative interactions, and social cohesiveness (Beech \& Mitchell, 2005; Insel \& Winslow, 1998; Rademacher, Anderson, \& Steinpreis, 2002), which is intriguingly similar to the increased sense of social closeness experienced by humans treated with selective serotonin reuptake inhibitors (SSRIs) (Knutson et al., 1998; Tse \& Bond, 2002) or using serotonergic agents such as "ecstasy" (MDMA) (Reneman et al., 2002). In a rodent study, animals reared in isolation were found to have a significant increase in $5 \mathrm{HT} 2 \mathrm{~A}$ receptor $\left(5 \mathrm{HT}_{2 \mathrm{~A}}\right)$ binding density in the rostral regions of the prelimbic cortex, rostral motor cortex, and cingulate cortices as compared to those reared socially (Preece, Dalley, Theobald, Robbins, \& Reynolds, 2004). Taken together, this literature suggests that the serotonin system might be relevant in mediating the desire for social relationships within the $\mathrm{OFC}$ and ACC.

Positron emission tomography (PET) imaging offers a minimally invasive means of exploring distinct properties and cerebral distribution of neurotransmitter systems through the binding of receptor specific radiotracers. Binding potential is a measure in
PET imaging studies that reflects both the density of available neuroreceptors and the affinity of a radiotracer to a given receptor (Innis et al., 2007). We are aware of only one study that has investigated the relation between serotonin receptor properties and temperament traits through in vivo binding of $\left[{ }^{18} \mathrm{~F}\right]$ fluoro-ethyl-spiperone (FESP) (Moresco et al., 2002). Using the Temperament and Character Inventory (TCI), Moresco and colleagues did not observe any significant correlation between the reward dependence (RD) scale (a measure that reflects the subjective reward value of social relationships) and $\left[{ }^{18} \mathrm{~F}\right]$ FESP binding in any region of interest (ROI), including the ACC. This study was limited by the small number of subjects $(n=11)$ and the use of a nonspecific radiotracer that binds to both cortical $5 \mathrm{HT}_{2}$ and striatal $\mathrm{D}_{2}$ receptors. We therefore sought to examine the neurochemical basis of social dependence in healthy normal subjects using the established $5 \mathrm{HT}_{2 \mathrm{~A}}$-specific radiotracer, $\left[{ }^{18} \mathrm{~F}\right]$ setoperone (Chow et al., 2009; Kapur, Jones, DaSilva, Wilson, \& Houle, 1997; Meyer et al., 1999).

Based on the independent roles established for the serotonergic system and the OFC and ACC in social behavior, we wished to explore the relationship between desire for social relationships (as measured by $\mathrm{RD}$ scores) and $5 \mathrm{HT}_{2 \mathrm{~A}}$ binding in these regions. Individuals who score high on RD are characterized as desirous of social closeness, eager to help and please others, sympathetic, sentimental, and sensitive to praise and signs of rejection. Conversely, those who score low on RD are socially and emotionally detached, content to be alone, practical, self-reliant, and independent. They are insensitive to social cues and pressures, and quick to discontinue relationships that are no longer gratifying (Cloninger, 1987).

\section{METHOD}

\section{Participants}

The study was approved by the Research Ethics Board of the Centre for Addictions and Mental Health, Toronto. Twenty-four healthy subjects (12 male and 12 female, age range $=18-50$ years, mean age $=35.3$ years, $S D=10.1$ ) were recruited by advertisement. Written informed consent was obtained after full explanation of the study procedures and risks. An assessment of psychiatric disorders was performed using the MINI-Plus structured interview (Sheehan et al., 1998). Subjects with serious or unstable medical or neurological conditions; substance abuse other than caffeine or nicotine within six months of the 
study; or either current or past axis I psychiatric diagnoses were excluded. Subjects received routine blood tests and urinalysis. Urine toxicology screens were done as part of the initial assessment and immediately before PET scans. Serum $\beta H C G$ levels were acquired to exclude pregnancy. Standard urine pregnancy tests were performed before each scan.

Participants were administered the TCI and the Karolinska Scales of Personality (KSP) prior to undergoing a $\left[{ }^{18} \mathrm{~F}\right]$ setoperone PET scan.

\section{PET data acquisition}

PET scanning was done with a Siemens brain-dedicated high resolution research tomography (HRRT) system (Siemens Molecular Imaging, Knoxville, TN) measuring radioactivity in 207 brain sections with a thickness of 1.2 $\mathrm{mm}$ each and an in-plane resolution of approximately $2.8 \mathrm{~mm}$ full width at half-maximum (FWHM). Transmission scans were acquired immediately before emission scans using a single photon point source $\left({ }^{137} \mathrm{Cs} ; t_{1 / 2}=30.2\right.$ years, $\left.\mathrm{E} \gamma=662 \mathrm{keV}\right)$; these were used to correct the emission scans for the attenuation of $511 \mathrm{keV}$ photons through tissue and head support. A saline solution containing a mean dose of $4.8 \mathrm{mCi}$ $\left[{ }^{18} \mathrm{~F}\right]$ setoperone $(S D=0.2)$, prepared in our laboratory as previously described (Chow et al., 2009), with a specific activity of $823 \mathrm{mCi} / \mu \mathrm{mol}(S D=619)$ was injected as a bolus into an intravenous line placed in an antecubital vein. Emission data were acquired in list mode for the highest possible temporal resolution. Emission data were acquired over $90 \mathrm{~min}$ for the $\left[{ }^{18} \mathrm{~F}\right]$ setoperone scans. Raw data were reconstructed by filtered-back projection to yield dynamic images. The $\left[{ }^{18} \mathrm{~F}\right]$ setoperone images were in 22 frames (five 1-min and 17 5-min frames).

Participants underwent standard magnetic resonance imaging (MRI) fast spin echo T1-weighted imaging (fast spoiled gradient echo, $\mathrm{TE}=5.3-15 \mathrm{~ms}$, $\mathrm{TR}=8.9-12 \mathrm{~ms}, \mathrm{FOV}=20 \mathrm{~cm} 3 \mathrm{D}, 256 \times 256$, voxel $1.5 \mathrm{~mm}$ isotropic, NEX = 1) acquired on a $1.5 \mathrm{~T}$ Sigma-GE scanner (General Electric Medical Systems, Milwaukee, WI). The T1 image was used for the analysis of the PET $\left[{ }^{18} \mathrm{~F}\right]$ setoperone scans.

\section{PET data analysis}

The outcome measure was the nondisplaceable binding potential $\left(\mathrm{BP}_{\mathrm{nd}}\right)$ as estimated using the simplified reference tissue method (SRTM) (Lammertsma \& Hume, 1996) with the cerebellar cortex as reference region. This method has been validated to reliably estimate the $\mathrm{BP}_{\mathrm{nd}}$, which compares the concentration of radioligand in the receptor-rich region to the receptor-free region (Innis et al., 2007), and has been used with $\left[{ }^{18} \mathrm{~F}\right]$ setoperone (Mamo et al., 2004, 2007).

\section{ROI approach}

Time activity curves (TACs) from the dynamic PET data were obtained using an in-house software for semiautomatic ROI delineation (Rusjan et al., 2006). This software, in concert with SPM2 (SPM2, Welcome Department of Cognitive Neurology, London; www.fil.ion.ucl.ac.uk/spm), (1) transforms a standardized brain template with a set of predefined ROIs to match each individual's high-resolution MRI, (2) refines the ROIs from the transformed template based on the gray matter probability of voxels in the individual MR images (segmentation step), (3) coregisters the individual MR images to the PET images for transfer of MRI-based ROIs to the PET image space, and (4) obtains a TAC from each of the defined ROIs in the native PET image space. The ROIs were the ACC (BA 32) and OFC (BA 11 and 47). The cerebellar cortex, excluding the vermix, was used as the reference region for the PET scans (Blin et al., 1990; Hall, Farde, Halldin, Lundkvist, \& Sedvall, 2000). The $\mathrm{BP}_{\mathrm{nd}}$ values were estimated using the PMOD v2.7 software (PMOD Technologies, Zurich, Switzerland).

\section{Voxel-wise approach}

Parametric voxel-wise $\mathrm{BP}_{\mathrm{nd}}$ maps from the dynamic images in native space were generated according to the method of Gunn, Lammertsma, Hume, \& Cunningham (1997) with the cerebellum as reference region. This was also performed using PMOD v2.7 software. The $\mathrm{BP}_{\mathrm{nd}}$ map images were spatially normalized into the Montreal Neurological Institute (MNI) brain space by nearest neighbor interpolation with a voxel size fixed at $2 \times 2 \times 2 \mathrm{~mm}$ using the SPM2 software (Friston, 1995). The normalized images were smoothed with a Gaussian filter in each coordinate direction with a kernel of $8 \mathrm{~mm}$ (two to three times the FWHM).

\section{Statistical analyses}

Statistical analyses were performed using SPSS v13.0 software. Partial Spearman correlations controlling for the effect of age were conducted to examine the relationship between $\mathrm{RD}$ and $\mathrm{BP}_{\mathrm{nd}}$ within each ROI. Age was controlled for due to its strong negative association with $5 \mathrm{HT}_{2 \mathrm{~A}}$ receptor binding potential (Bhagwagar, 
2006; Meyer et al., 2003). Spearman correlations (nonparametric) rather than Pearson coefficients were used due to the relatively small sample size. The statistical threshold was established with $p \leq 0.025$ in order to control for multiple comparisons, $p=0.05 / 2$ ROI (ACC and OFC). In order to give face validity to our hypothesis we also analyzed the detachment scale of the KSP. Although the detachment and RD scales have not previously been correlated in the literature, conceptually they both measure the spectrum of social dependence and social detachment. These scales are inversely related due to their respective directions of measurement.

A confirmatory voxel-wise correlation between $\mathrm{BP}_{\mathrm{nd}}$ maps and $\mathrm{RD}$ was performed with age as covariate employing a single subject with covariates model as implemented in SPM2 (www.fil.ion.ucl.ac.uk/spm) (Friston, 1995). We reported areas only if they met the joint criteria of: (a) $p$ (uncorrected) $<0.001$; (b) an extent $>9$ voxels ( $\sim 3$ times FWHM); (c) occurring in the ACC (BA 32) and OFC (BA 11 and 47); and (d) $p$ (corrected) $<0.005$ using the false discovery rate (FDR) approach to control for multiple comparisons.

\section{RESULTS}

The mean RD score was $14.9, \mathrm{SD}=4.6$. Statistical analysis of the ROIs demonstrated an inverse relationship between RD score and $5 \mathrm{HT}_{2 \mathrm{~A}} \mathrm{BP}_{\mathrm{nd}}$ in the $\mathrm{ACC}$
(BA 32, $r=-0.528, p=0.012, d f=20)$ and OFC (BA $11, r=-0.489, p=0.021, d f=20$; BA 47, $r=-0.501$, $p=0.017, d f=20$ ). These results confirm our hypothesis of an association between the desire for social relationships and serotonin binding in the OFC and ACC (Table 1). A voxel-wise analysis of the relationship between $5 \mathrm{HT}_{2 \mathrm{~A}} \mathrm{BP}_{\mathrm{nd}}$ and $\mathrm{RD}$ scores, controlling for age as a covariate, supports the primary results (Table 2). No positive correlations were identified. A correlation map controlling for age as a covariate is presented in Figure 1 to illustrate the association in the a priori areas.

As expected, we also observed a strong negative correlation between the KSP detachment scale and RD scores $(r=-0.61, p=0.002, n=23)$. Scores on the detachment scale were positively correlated with $5 \mathrm{HT}_{2 \mathrm{~A}} \mathrm{BP}_{\mathrm{nd}}$ in the OFC (BA 11, $r=0.425, p=0.043$, $d f=21)$. This did not reach statistical significance after

TABLE 1

ROI analysis: Partial Spearman coefficients between mean $5 \mathrm{HT}_{2 \mathrm{~A}} \mathrm{BP}_{\mathrm{nd}}$ in the regions of interest and $\mathrm{RD}$ scores, controlling for age as a covariate

\begin{tabular}{lcccccc}
\hline Region & $B A$ & Mean $B P_{n d}$ & Volume $\left(\mathrm{mm}^{3}\right)$ & $r$ & $P$ & $d f$ \\
\hline OFC & 11 & $1.53 \pm 1.42$ & 67432 & -0.489 & 0.021 & 20 \\
OFC & 47 & $1.44 \pm 1.41$ & 34512 & -0.501 & 0.017 & 20 \\
ACC & 32 & $1.44 \pm 1.40$ & 34952 & -0.528 & 0.012 & 20 \\
\hline
\end{tabular}

Notes: $\mathrm{BA}$, Brodmann area; $\mathrm{BP}_{\mathrm{nd}}$, nondisplaceable binding potential; OFC, orbitofrontal cortex; ACC, anterior cingulate cortex.

TABLE 2

Voxel-wise analysis. Correlations between $5 \mathrm{HT}_{2 \mathrm{~A}} \mathrm{BP}_{\mathrm{nd}}$ and $\mathrm{RD}$ scores, controlling for age as a covariate

\begin{tabular}{|c|c|c|c|c|c|c|c|c|}
\hline \multirow[b]{2}{*}{ Region } & \multirow[b]{2}{*}{$B A$} & \multicolumn{3}{|c|}{ MNI Coordinates } & \multirow{2}{*}{$\begin{array}{c}\text { Voxels } \\
\text { per cluster }\end{array}$} & \multicolumn{3}{|c|}{ Statistic } \\
\hline & & $x$ & $y$ & $z$ & & $t$ & $p_{\text {uncorr }}$ & $p_{\text {corr }}(F D R)$ \\
\hline Left caudate head & & -8 & 10 & 12 & 76 & 7.22 & 0.000 & 0.004 \\
\hline Right Inferior Frontal & 45 & 46 & 34 & 4 & 27 & 7.02 & 0.000 & 0.004 \\
\hline Left anterior cingulate & 32 & -12 & 44 & 30 & 61 & 6.77 & 0.000 & 0.004 \\
\hline Left orbitofrontal & 11 & -16 & 50 & -8 & 77 & 6.75 & 0.000 & 0.004 \\
\hline Right lentiform nucleus & & 28 & -2 & 6 & 83 & 6.48 & 0.000 & 0.004 \\
\hline Right caudate & & 16 & 4 & 18 & 21 & 6.42 & 0.000 & 0.004 \\
\hline Right anterior cingulate & 32 & 4 & 40 & -2 & 42 & 6.20 & 0.000 & 0.004 \\
\hline Right orbitofrontal/Insula & $47 / 48$ & 30 & 22 & 8 & 140 & 6.16 & 0.000 & 0.004 \\
\hline Left Orbitofrontal & 11 & -6 & 32 & -30 & 61 & 6.13 & 0.000 & 0.004 \\
\hline Left precentral & 4 & -56 & -14 & 32 & 21 & 6.11 & 0.000 & 0.004 \\
\hline Right insula & 48 & 38 & -14 & -2 & 50 & 6.06 & 0.000 & 0.004 \\
\hline Anterior cingulate & 32 & 0 & 40 & 10 & 19 & 5.71 & 0.000 & 0.004 \\
\hline Left postcentral & 3 & -42 & -24 & 46 & 25 & 5.71 & 0.000 & 0.004 \\
\hline Right precentral & 6 & 32 & -12 & 60 & 23 & 5.67 & 0.000 & 0.004 \\
\hline Right anterior cingulate & 32 & 12 & 40 & 16 & 27 & 5.62 & 0.000 & 0.004 \\
\hline Left inferior frontal & 44 & -50 & 8 & 22 & 44 & 5.60 & 0.000 & 0.004 \\
\hline Left precentral & 4 & -52 & -16 & 42 & 15 & 5.44 & 0.000 & 0.004 \\
\hline Left superior temporal & 41 & -44 & -34 & 10 & 18 & 5.30 & 0.000 & 0.004 \\
\hline
\end{tabular}

Notes: $\mathrm{BP}_{\mathrm{nd}}$, nondisplaceable binding potential; $\mathrm{RD}$, reward dependence. Bold type indicates regions of interest. 


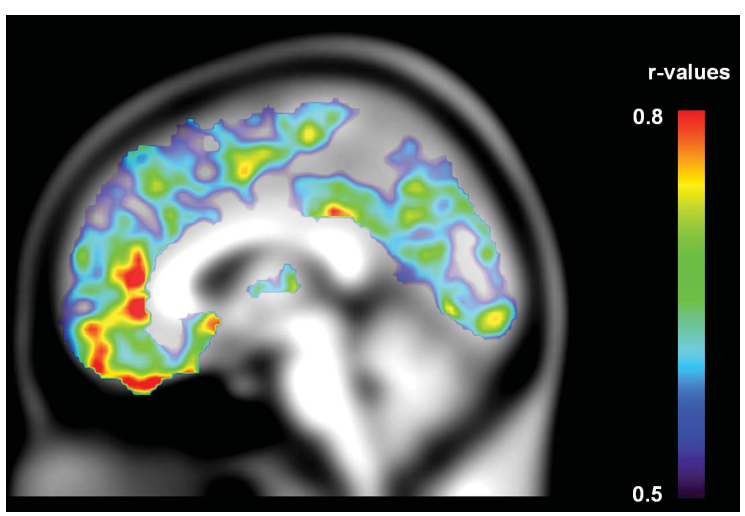

Figure 1. Correlation image of $5 \mathrm{HT}_{2 \mathrm{~A}} \mathrm{BP}_{\mathrm{nd}}$ maps and RD scores, controlling for age as a covariate. Sagital projection overlay of 24 controls on a T1 average template in the MNI space. $r$, Pearson's correlation coefficient.

controlling for multiple comparisons. Trend-level positive correlations were found for the KSP detachment scale and $5 \mathrm{HT}_{2 \mathrm{~A}} \mathrm{BP}_{\mathrm{nd}}$ in BA $47(r=0.364, p=0.088$, $d f=21)$ and BA $32(r=0.346, p=0.106, d f=21)$.

Setoperone $\mathrm{BP}_{\mathrm{nd}}$ was generally found to be higher in males than females; however, this did not reach statistical significance in any ROI when the relationship between gender and $\mathrm{BP}_{\mathrm{nd}}$ was assessed through a series of Mann-Whitney $U$-tests. Our sample size is likely too small to adequately test for gender differences.

\section{DISCUSSION}

These results support a central role for the serotonin system in mediating the desire for social relationships within the OFC and ACC. This is consistent with a rich literature that substantiates the modulatory effects of serotonin on social behavior. Low serotonin function has been associated with impulsivity (a lack of either constraint or an ability to delay gratification) (Carver \& Miller, 2006), aggression and antisocial behavior in pathological (Coccaro, Kavoussi, Cooper, \& Hauger, 1997; Dolan, Anderson, \& Deakin 2001; Paris et al., 2004; Soloff, Kelly, Strotmeyer, Malone, \& Mann, 2003) and healthy populations (Cleare \& Bond, 1997; Hennig, Reuter, Netter, Burk, \& Landt, 2005). Conversely, elevated serotonin function is associated with social attachment and prosocial behavior in both humans and primates (Cherek, Lane, Pietras, \& Steinberg, 2002; Insel \& Winslow, 1998; Knutson et al., 1998; Rademacher et al., 2002; Tse \& Bond, 2002). Similar results have been observed in studies manipulating tryptophan (a precursor of serotonin) levels in humans, whereby tryptophan enhancement resulted in less aggression and tryptophan depletion led to increased hostility (Bjork, Dougherty, Moeller, \& Swann, 2000; Marsh, Dougherty, Moeller, Swann, \& Spiga, 2002). Other PET imaging studies also support the theory of serotonergic regulation of social behavior occurring predominantly in the OFC and ACC. Persons with a history of impulsive aggression had decreased serotonin transporter availability in the ACC (Frankle et al., 2005), and reduced cerebral metabolism in the left OFC and ACC following the administration of a serotonergic stimulus (New et al., 2002). Our results indicate an inverse relationship between $5 \mathrm{HT}_{2 \mathrm{~A}}$ and $\mathrm{BP}_{\mathrm{nd}}$ within the $\mathrm{OFC}$ and $\mathrm{ACC}$ and $\mathrm{RD}$, which may reflect alterations of serotonergic function in these regions (Meyer et al., 2001; Yatham et al., 1999).

As a measure of the reward value of social relationships, RD closely resembles the construct of attachment (Bowlby, 1988), which characterizes the degree of proximity seeking or avoidance of caregivers during stressful situations. To date, no human studies have investigated the possible link between social attachment and prefrontal $5 \mathrm{HT}_{2 \mathrm{~A}}$ binding potential. In concordance with our findings, functional imaging research has found that attachment is associated with activity in the OFC and the ACC. A functional MRI (fMRI) study of human maternal attachment responses to infant cries showed activation in the ACC and OFC (BA10 and BA 11) (Lorberbaum et al., 1999). Another fMRI study of maternal attachment showed that mothers exhibited bilateral activation of the OFC while viewing pictures of their own vs. unfamiliar infants (Nitschke et al., 2004). Activation of the ACC has also been associated with the subjective experience of social distress due to interpersonal rejection. Participants who reported feeling more distress during a scanner-based rejection paradigm demonstrated greater ACC activation (Eisenberger, Gable, Lieberman, 2007; Eisenberger, Lieberman, \& Williams, 2003), which correlated with greater momentary distress during daily social interactions (Eisenberger et al., 2007). Interestingly, in a PET study by Farde, Gustavsson, \& Jonsson (1997), an inverse relationship was reported between dopamine type-2 receptor density and the KSP detachment scale. Taken together with our results, this suggests that a reciprocal relationship may exist between the serotonergic and dopaminergic systems in the regulation of social attachment.

The OFC and ACC are integral in decision-making and the appraisal of rewarding or punishing stimuli (Harris et al., 2007). This evaluative function is critical to the determination of social valence and to the successful formation and maintenance of relationships. ACC and OFC dysfunction, either structurally 
(e.g. lesion) or neurochemically (e.g. hyposerotonergic state), results in impaired regulation of primitive subcortical impulses and behaviors that would normally conflict with long-term rewards or consequences. The survival value of social relationships and group conformity is unappreciated, leaving the individual, in extreme cases, in a state of disinhibited self-interest and self-reliance; while lacking foresight and social cognition. Lesion studies highlight the role of the OFC and ACC regions in social behavior (Hornak et al., 2003). In comparison with subjects with other frontal lesions, subjects with bilateral surgical excisions of the OFC scored lower on a test of social behavior, as did subjects with combined unilateral OFC and BA 9/ACC lesions.

Our findings have implications for acquired and neurodegenerative disorders with impaired social behavior as a result of damage to the OFC and ACC. Lack of sentimentality, empathy, emotional and social detachment are predominant features of frontotemporal lobar degeneration (FTD) and figure in the diagnosis of frontal variant Alzheimer's disease (AD) (McKhann et al., 2001; Neary et al., 1998; Snowden et al., 2001; Taylor, Probst, Miserez, Monsch, \& Markus, 2008). In contrast to our findings, reduced serotonin receptor binding is associated with the progression of both AD and the frontal variant of FTD (Salmon, 2007). A number of PET studies that measured alterations in $5 \mathrm{HT}_{2 \mathrm{~A}}$ binding in these conditions found reduced receptor availability in several regions, including the prefrontal cortex (Blin et al., 1993; Franceschi et al., 2005). Serotonin receptor reduction, however, is also associated with normal aging (Meltzer et al., 1998). Moreover, the degree to which changes in serotonin receptor binding are accounted for by volumetric changes secondary to atrophy in these dementia types is unclear (Blin et al., 1993). Nonetheless, neurodegenerative changes to the serotonergic system within the ACC and OFC may, in part, explain the impaired social behavior that can occur in these forms of dementia.

The results of our study also lend support to further investigation of serotonergic agents for their prosocial effects. There is preliminary evidence that SSRIs are efficacious for the treatment of behavioral disturbances in dementia (Pollock et al., 2002) and traumatic brain injury (Kant, Smith-Seemiller, \& Zeiler, 1998). Some data also supports their use in individuals with aberrant, antisocial behavior in both the adult and pediatric populations (Armenteros \& Lewis, 2002; Cherek et al., 2002). Although little to no data exists, development of regionally specific serotonergic agents may theoretically benefit individuals who are socially detached or who have marked social and interpersonal deficits, e.g., autism (Posey, Erickson, $\&$ McDougle, 2008), schizophrenia (Sepehry, Potvin, Elie, \& Stip, 2007), schizoid, schizotypal (Markovitz, Calabrese, Schulz, \& Meltzer, 1991), avoidant, and borderline personality disorders (Mercer, 2007).

The main limitation of our study is that it is restricted to healthy normal subjects. Replication of our observations in healthy and pathological samples using other measures specific to attachment and social behavior is necessary to support our hypothesis. It is important to note that $5 \mathrm{HT}_{2 \mathrm{~A}}$ receptors are ubiquitous in the human brain, having highest density in the cortex and intermediate density in the basal ganglia, with only slight regional differences (Pazos, Probst, \& Palacios, 1987; Schotte, Maloteaux, \& Laduron, 1983). While we obtained significant correlations in our a priori ROIs, other regions correlated as well (Table 2). Consequently, the relationship between $5 \mathrm{HT}_{2 \mathrm{~A}}$ binding and RD scores could be a more generalized phenomenon within the brain, with different degrees of correlation between regions. This hypothesis requires investigation in future studies with larger sample sizes.

In conclusion, our results demonstrated an inverse association between desire for social relationships and $5 \mathrm{HT}_{2 \mathrm{~A}}$ binding in the OFC and ACC. These results suggest that the serotonergic system may have a regulatory effect on the OFC and ACC for establishing and maintaining social relationships, and add to the body of literature that implicates the serotonin system and these regions in social behavior.

Manuscript received 4 September 2008 Manuscript accepted 17 November 2008 First published online

\section{REFERENCES}

Armenteros, J. L., \& Lewis J. E. (2002). Citalopram treatment for impulsive aggression in children and adolescents: An open pilot study. Journal of the American Academy of Child and Adolescent Psychiatry, 41, 522-529.

Beech, A. R., \& Mitchell, I. J. (2005). A neurobiological perspective on attachment problems in sexual offenders and the role of selective serotonin re-uptake inhibitors in the treatment of such problems. Clinical Psychology Review, 25, 153-182.

Bhagwagar, Z., Hinz, R., Taylor, M., Fancy, S., Cowen, P., \& Grasby, P. (2006). Increased 5-HT(2A) receptor binding in euthymic, medication-free patients recovered from depression: A positron emission study with [(11)C]MDL 100,907. American Journal of Psychiatry, 163(9), 1580-1587.

Bjork, J. M., Dougherty, D. M., Moeller, F. G., \& Swann, A. C. (2000). Differential behavioral effects of plasma tryptophan 
depletion and loading in aggressive and nonaggressive men. Neuropsychopharmacology, 22, 357-369.

Blin, J., Baron, J. C., Dubois, B., Crouzel, C., Fiorelli, M., Attar-Levy, D., et al. (1993). In vivo assessment with positron emission tomography and $[18 \mathrm{~F}]$ setoperone. Brain, 116(3), 497-510.

Blin, J., Sette, G., Fiorelli, M., Bletry, O., Elghozi, J. L., Crouzel, C., et al. (1990). A method for the in vivo investigation of the serotonergic 5-HT2 receptors in the human cerebral cortex using positron emission tomography and 18F-labeled setoperone. Journal of Neurochemistry, 54, 1744-1754.

Bowlby, J. (1988). A secure base: Clinical applications of attachment theory. London: Routledge.

Carver, C. S., \& Miller, C. J. (2006). Relations of serotonin function to personality: Current views and a key methodological issue. Psychiatry Research, 144, 1-15.

Cassidy, J., \& Shaver, P. (Eds.). (1999). Handbook of attachment: Theory, research, and clinical applications. New York: Guilford Press.

Cherek, D. R., Lane S. D., Pietras, C. J., \& Steinberg, J. L. (2002). Effects of chronic paroxetine administration on measures of aggressive and impulsive responses of adult males with a history of conduct disorder. Psychopharmacology, 159, 266-274.

Chow, T. W., Mamo, D. C., Uchida, H., Graff-Guerrero, A., Houle, S., Smith, G. S., et al. (2009). Test-retest variability of high resolution positron emission tomography (PET) imaging of cortical serotonin (5HT2A) receptors in older, healthy adults. BMC Medical Imaging, 9, 12.

Cleare, A. J., \& Bond, A. J. (1997). Does central serotonergic function correlate inversely with aggression? A study using D-fenfluramine in healthy subjects. Psychiatry Research, 69, 89-95.

Cloninger, C. R. (1987). A systematic method for clinical description and classification of personality variants. Archives of General Psychiatry, 44, 573-588.

Cloninger, C. R., Svrakic D. M., \& Przybeck, T. R. (1993). A psychobiological model of temperament and character. Archives of General Psychiatry 50, 975-990.

Coccaro, E. F., Kavoussi, R. J., Cooper, T. B., \& Hauger, R. L. (1997). Central serotonin activity and aggression: Inverse relationship with prolactin response to d-fenfluramine, but not CSF 5- HIAA concentration, in human subjects. American Journal of Psychiatry, 154, 1430-1435.

Dolan, M. C., Anderson I. M., \& Deakin, J. F. W. (2001). Relationship between 5-HT function and impulsivity and aggression in male offenders with personality disorders. British Journal of Psychiatry, 178, 352-359.

Eisenberger, N. I., Gable, S. L., \& Lieberman, M. D. (2007). Functional magnetic resonance imaging responses relate to differences in real-world social experience. Emotion, 4, 745-754.

Eisenberger, N. I., Lieberman, M. D., \& Williams, K. D. (2003). Does rejection hurt? An fMRI study of social exclusion. Science, 302, 290-292.

Farde, L., Gustavsson, J. P., \& Jonsson, E. (1997). D2 dopamine receptors and personality traits. Nature, 385,590 .

Franceschi, M., Anchisi, D., Pelati, O., Zuffi, M., Matarrese, M., Moresco, R. M., et al. (2005). Glucose metabolism and serotonin receptors in the frontotemporal lobe degeneration. Annals of Neurology, 57, 216-225.
Frankle, W. G., Lombardo, I., New, A. S., Goodman, M., Talbot, P. S., Huang, Y. (2005). Brain serotonin transporter distribution in subjects with impulsive aggressivity: A positron emission study with [11C]McN 5652. American Journal of Psychiatry, 162, 915-923.

Friston, K. J. (1995). Commentary and opinion: II. Statistical parametric mapping: Ontology and current issues. Journal of Cerebral Blood Flow and Metabolism, 15(3), 361-370.

Graff-Guerrero, A., Gonzalez-Olvera, J., MendozaEspinosa, Y., Vaugier, V., \& Garcia-Reyna, J. C. (2004). Correlation between cerebral blood flow and items of the Hamilton Rating Scale for Depression in antidepressant-naive patients. Journal of Affective Disorders, 80(1), 55-63.

Gunn, R. N., Lammertsma, A. A., Hume, S. P., \& Cunningham, V. J. (1997). Parametric imaging of ligand-receptor binding in PET using a simplified reference region model. NeuroImage, 6(4), 279-287.

Hall, H., Farde, L., Halldin, C., Lundkvist, C., \& Sedvall, G. (2000). Autoradiographic localization of 5-HT(2A) receptors in the human brain using [(3)H]M100907 and [(11)C]M100907. Synapse, 38, 421-431.

Hampton, A. N., O'Doherty JP. (2007). Decoding the neural substrates of reward-related decision making with functional MRI. Proceedings of the National Academy of Sciences of the United States of America, 104, 1377-1382.

Harris, L. T., McClure, S. M., van den Bos, W., Cohen, J. D., \& Fiske, S. T. (2007). Regions of the MPFC differentially tuned to social and nonsocial affective evaluation. Cognitive, Affective \& Behavioral Neuroscience, 7(4), 309-316.

Hennig, J., Reuter, M., Netter, P., Burk, C., \& Landt, O. (2005). Two types of aggression are differentially related to serotonergic activity and the A779C TPH polymorphism. Behavioral Neuroscience, 119, 16-25.

Hornak, J., Bramham, J., Rolls, E. T., Morris, R. G., O'Doherty, J., Bullock, P. R., et al. (2003). Changes in emotion after circumscribed surgical lesions of the orbitofrontal and cingulate cortices. Brain, 126, 1691-1712.

Innis, R. B., Cunningham, V. J., Delforge, J., Fujita, M., Gjedde, A., Gunn, R. N., et al. (2007). Consensus nomenclature for in vivo imaging of reversibly binding radioligands. Journal of Cerebral Blood Flow and Metabolism, 27(9), 1533-1539.

Insel, T. R., \& Winslow, J. T. (1998). Serotonin and neuropeptides in affiliative behaviors. Biological Psychiatry, 44, 209-217.

Kant, R., Smith-Seemiller, L., \& Zeiler, D. (1998). Treatment of aggression and irritability after head injury. Brain Injury, 12, 661-666.

Kapur, S., Jones, C., DaSilva, J., Wilson, A., \& Houle, S. (1997). Reliability of a simple non-invasive method for the evaluation of 5-HT2 receptors using [18F]-setoperone PET imaging. Nuclear Medicine Communications, 18(5), 395-399.

Knutson, B., Wolkowitz, O. M., Cole, S. W., Chan, T., Moore, E. A., Johnson, R. C., et al. (1998). Selective alteration of personality and social behavior by serotonergic intervention. American Journal of Psychiatry, 155 , 373-379.

Kringelbach, M. L. (2005). The human orbitofrontal cortex: Linking reward to hedonic experience. Nature Reviews Neuroscience, 6, 691-702. 
Lammertsma, A. A., \& Hume, S. P. (1996). Simplified reference tissue model for PET receptor studies. NeuroImage, 4, 153-158.

Lorberbaum, J. P., Newman, J. D., Dubno, J. R., Horwitz, A. R., Nahas, Z., Teneback, C. C., et al. (1999). Feasibility of using fMRI to study mothers responding to infant cries. Depression and Anxiety, 10, 99-104.

Mamo, D., Graff, A., Mizrahi, R., Shammi, C. M., Romeyer, F., \& Kapur, S. (2007). Differential effects of aripiprazole on $\mathrm{D}(2), 5-\mathrm{HT}(2)$, and 5-HT(1A) receptor occupancy in patients with schizophrenia: A triple tracer PET study. American Journal of Psychiatry, 164(9), 1411-1417.

Mamo, D., Kapur, S., Shammi, C. M., Papatheodorou, G., Mann, S., Therrien, F., et al. (2004). A PET study of dopamine D2 and serotonin 5-HT2 receptor occupancy in patients with schizophrenia treated with therapeutic doses of ziprasidone. American Journal of Psychiatry, 161(5), 818-825.

Markovitz, P. J., Calabrese, J. R., Schulz, S. C., \& Meltzer, H. Y. (1991). Fluoxetine in the treatment of borderline and schizotypal personality disorders. American Journal of Psychiatry, 148, 1064-1067.

Marsh, D. M., Dougherty, D. M., Moeller, F. G., Swann, A. C., \& Spiga, R. (2002). Laboratory-measured aggressive behavior of women: Acute tryptophan depletion and augmentation. Neuropsychopharmacology, 26, 660-671.

McKhann, G. M., Albert, M. S., Grossman, M., Miller, B., Dickson, D., Trojanowski, J. Q., et al. (2001). Clinical and pathological diagnosis of frontotemporal dementia: Report of the Work Group on Frontotemporal Dementia and Pick's Disease. Archives of Neurology, 58, 1803-1809.

Meltzer, C. C., Smith, G., Price, J. C., Reynolds, C. F., 3rd, Mathis, C. A., Greer, P., et al. (1998). Reduced binding of $[18 \mathrm{~F}]$ altanserin to serotonin type $2 \mathrm{~A}$ receptors in aging: Persistence of effect after partial volume correction. Brain Research, 813, 167-171.

Mercer, D. (2007). Medications in the treatment of borderline personality disorder 2006. Current Psychiatry Reports, 9, 53-62.

Meyer, J. H., Kapur, S., Eisfeld, B., Brown, G. M., Houle, S., DaSilva, J., et al. (2001). The effect of paroxetine on 5-HT(2A) receptors in depression: An [(18)F]setoperone PET imaging study. American Journal of Psychiatry, 158(1), 78-85.

Meyer, J. H., Kapur, S., Houle, S., DaSilva, J., Owczarek, B., Brown, G. M., et al. (1999). Prefrontal cortex 5-HT2 receptors in depression: An [18F]setoperone PET imaging study. American Journal of Psychiatry, 156(7), 1029-1034.

Meyer, J. H., McMain, S., Kennedy, S. H., Korman, L., Brown, G. M., DaSilva, J. N., et al. (2003). Dysfunctional attitudes and 5-HT2 receptors during depression and selfharm. American Journal of Psychiatry 160, 90-99.

Moresco, F., Dieci, M., Vita, A., Messa, C., Gobbo, C., Galli, L., et al. (2002). In vivo serotonin 5HT(2A) receptor binding and personality traits in healthy subjects: A positron emission tomography study. NeuroImage, 17(3), 1470-1478.

Neary, D., Snowden, J. S., Gustafson, L., Passant, U., Stuss, D., Black, S., et al. (1998). Frontotemporal lobar degeneration: A consensus on clinical diagnostic criteria. $\mathrm{Neu}$ rology, 51, 1546-1554.
New, A. S., Hazlett, E. A., Buchsbaum, M. S., Goodman, M., Reynolds, D., Mitropoulou, V., et al. (2002). Blunted prefrontal cortical 18fluorodeoxyglucose positron emission tomography response to meta chlorophenylpiperazine in impulsive aggression. Archives of General Psychiatry, 59, 621-629.

Nitschke, J. B., Nelson, E. E., Rusch, B. D., Fox, A. S., Oakes, T. R., \& Davidson, R. J. (2004). Orbitofrontal cortex tracks positive mood in mothers viewing pictures of their newborn infants. NeuroImage, 21, 583-592.

Noriuchi, M., Kikuchi, Y., \& Senoo, A. (2008). The functional neuroanatomy of maternal love: Mother's response to infant's attachment behaviors. Biological Psychiatry, 63, 415-423.

Paris, J., Zweig-Frank, H., Ng Ying Kin, N. M. K., Schwartz, G., Steiger, H., \& Nair, N. P. V. (2004). Neurobiological correlates of diagnosis and underlying traits in patients with borderline personality disorder compared with normal controls. Psychiatry Research, 121, 239-252.

Pazos, A., Probst, A., \& Palacios, J. M. (1987). Serotonin receptors in the human brain-IV. Autoradiographic mapping of serotonin-2 receptors. Neuroscience, 21(1), 123-139.

Pollock, B. G., Mulsant, B. H., Rosen, J., Mazumdar, S., Blakesley, R. E., Houck, P. R., et al. (2007). A doubleblind comparison of citalopram and risperidone for the treatment of behavioral and psychotic symptoms associated with dementia. American Journal of Geriatric Psychiatry, 15, 942-952.

Pollock, B. G., Mulsant, B. H., Rosen, J., Sweet, R. A., Mazumdar, S., Bharucha, A., et al. (2002). Comparison of citalopram, perphenazine, and placebo for the acute treatment of psychosis and behavioral disturbances in hospitalized, demented patients. American Journal of Psychiatry, 159, 460-465.

Posey, D. J., Erickson, C. A., \& McDougle, C. J. (2008). Developing drugs for core social and communication impairment in autism. Child and Adolescent Psychiatric Clinics of North America, 17, 787-801.

Posner, M. I., Rothbart, M. K., \& Sheese, B. E. (2007). The anterior cingulate gyrus and the mechanism of selfregulation. Cognitive, Affective \& Behavioral Neuroscience, 7, 391-395.

Preece, M. A., Dalley, J. W., Theobald, D. E., Robbins, T. W., \& Reynolds, G. P. (2004). Region specific changes in forebrain 5-hydroxytryptamine1A and 5-hydroxytryptamine2A receptors in isolation-reared rats: An in vitro autoradiography study. Neuroscience, 123, 725-732.

Rademacher, D. J., Anderson, A. P., \& Steinpreis, R. E. (2002). Acute effects of amperozide and paroxetine on social cohesion in male conspecifics. Brain Research Bulletin, 58, 187-191.

Rainville, P., Duncan, G. H., Price, D. D., Carrier, B., \& Bushnell, M. C. (1997). Pain affect encoded in human anterior cingulate but not somatosensory cortex. Science, 277, 968-971.

Reneman, L., Endert, E., de Bruin, K., Lavalaye, J., Feenstra, M. G., de Wolff, F. A., et al. (2002). The acute and chronic effects of MDMA ("ecstasy") on cortical 5HT2A receptors in rat and human brain. Neuropsychopharmacology, 26(3), 387-396.

Rusjan, P., Mamo, D., Ginovart, N., Hussey, D., Vitcu, I., Yasuno, F., et al. (2006). An automated method for the 
extraction of regional data from PET images. Psychiatry Research, 147(1), 79-89.

Salmon, E. (2007). A review of the literature on neuroimaging of serotoninergic function in Alzheimer's disease and related disorders. Journal of Neural Transmission, 114, 1179-1185.

Schotte, A., Maloteaux, J. M., \& Laduron, P. M. (1983). Characterization and regional distribution of serotonin S2-receptors in human brain. Brain Research, 276(2), 231-235.

Sepehry, A. A., Potvin, S., Elie, R., \& Stip, E. (2007). Selective serotonin reuptake inhibitor (SSRI) add-on therapy for the negative symptoms of schizophrenia: A meta-analysis. Journal Clinical Psychiatry, 68(4), 604-610.

Sheehan, D. V., Lecrubier, Y., Sheehan, K. H., Amorim, P., Janavs, J., Weiller, E., et al. (1998). The MiniInternational Neuropsychiatric Interview (M.I.N.I.): The development and validation of a structured diagnostic psychiatric interview for DSM-IV and ICD-10. Journal of Clinical Psychiatry, 59(Suppl. 20), 22-33; quiz 34-57.

Snowden, J. S., Bathgate, D., Varma, A., Blackshaw, A., Gibbons, Z. C., \& Neary, D. (2001). Distinct behavioural profiles in frontotemporal dementia and semantic dementia. Journal of Neurology, Neurosurgery \& Psychiatry, 70, 323-332.

Soloff, P. H., Kelly, T. M., Strotmeyer, S. J., Malone, K. M., \& Mann, J. J. (2003). Impulsivity, gender, and response to fenfluramine challenge in borderline personality disorder. Psychiatry Research, 119, 11-24.

Taylor, K. I., Probst, A., Miserez, A. R., Monsch, A. U., \& Markus, T. (2008). Clinical course of neuropathologically confirmed frontal-variant Alzheimer's disease. Nature Clinical Practice Neurology, 4, 226-232.

Tse, W. S., \& Bond A. J. (2002). Serotonergic intervention affects both social dominance and affiliative behavior. Psychopharmacology, 161, 324-330.

Vogt, B. A. (2005). Pain and emotion interactions in subregions of the cingulate gyrus. Nature Reviews Neuroscience, 6(7), 533-544.

Yatham, L. N., Liddle, P. F., Dennie, J., Shiah, I. S., Adam, M. J., Lane, C. J., et al. (1999). Decrease in brain serotonin 2 receptor binding in patients with major depression following desipramine treatment: A positron emission tomography study with fluorine-18-labeled setoperone. Archives of General Psychiatry, 56(8), 705-711. 